\title{
TECNOLOGIA E IMPLICAÇÕES NA EDUCAÇÃO
}

\author{
Odete Catarina Locatelli ${ }^{1}$
}

Resumo: Esse artigo trata das Tecnologias da Informação e Comunicação (TICs), das possibilidades inéditas na interação entre as pessoas em diferentes áreas, num mundo cada vez mais globalizado, e sua inserção em diversas áreas do conhecimento, especialmente na educação. A evolução das tecnologias desde a invenção da imprensa, passando pela criação dos microcomputadores e a internet gerou um desenvolvimento cognitivo e relacional que coloca a necessidade de se qualificar minimamente novos profissionais de nível técnico e superior em todas as áreas para utilização das novas tecnologias.

Palavras-chave: Tecnologias da Informação e Comunicação; educação; paradigma. 


\section{Introdução}

As tecnologias sempre tiveram papel importante na organização das sociedades, na forma de interação entre o homem e a nature$\mathrm{za}$, em sua cultura e, atualmente, de modo particular, as tecnologias da informação, que permitem o armazenamento, a difusão e a elaboração do conhecimento. Podemos considerar como Lévy (1990), que as tecnologias da informação, ou conforme denomina o autor, as "tecnologias da inteligência" ou da "mente", cada vez mais presentes na sociedade, propiciam uma nova discussão em torno da filosofia do conhecimento. Por serem responsáveis por novas formas de elaboração e distribuição do saber, portanto, de comunicação, colocam em questão alguns pilares da epistemologia contemporânea, como a dualidade sujeito-objeto, mente-matéria.

O problema é a celeridade das transformações técnicas científicas em descompasso com as transformações culturais mais amplas. Esse descompasso amplia a margem de exclusão social. Lévy (1990) diz que o princípio de responsabilidade não representa unicamente a responsabilidade que temos com os outros, mas com as gerações futuras.

Em 1447, Gutenberg revolucionou a comunicação com o invento da prensa e dos tipos móveis, que permitiram uma maior circulação da informação. Utilizando-se do invento de Gutenberg, vários veículos de comunicação foram criados, como folhetins, jornais, catálogos e revistas.

$\mathrm{Na}$ época, a possibilidade do conhecimento ser impresso gerou resistências especialmente no meio educacional.

Dizem que na primeira reunião da congregação docente feita naquela casa do saber, em seguida à chegada da noticia do extraordinário acontecimento que se dera em Mainz, à desolação fora em geral. Os professores ingleses, desconsolados, acreditaram que, com a vinda dos livros impressos, eles não teriam mais função. No futuro, pensaram eles, qualquer um poderia adquirir um livro e aprenderiam tudo, por si mesmos. (SHILLING, 2006, p. 10). 
Após cinco séculos, o canadense Marschall Macluhan, inaugura a aldeia global. Essa expressão - aldeia global - significa que o processo tecnológico reduziria todo o planeta à mesma situação que ocorre em uma aldeia, ou seja, a possibilidade de se intercomunicar diretamente com qualquer pessoa que nela vive.

Em 1962, Macluhan estava se referindo à televisão como um meio de comunicação de massa capaz de encurtar as distâncias e o tempo via satélite. No entanto, somente agora, com as tecnologias de convergências, como o celular e a internet, é que o conceito começa a se concretizar.

Nas décadas de 80 e 90 aconteceu a explosão das TICs, das quais, citam-se: a telefonia celular, possibilitando a informação e criação de novas formas de relação pessoal e de trabalho, e a televisão por assinatura, atendendo a uma grande demanda por meio de canais especializados, como previsão de tempo, jornalismo, e possibilitando a realização de grandes eventos financeiros, que não movem sequer uma moeda, e sim bites, que representam valores inimagináveis.

Referindo-nos às TICs e os Ambientes Computacionais, podemos dizer que a evolução da eletrônica e das tecnologias de circuitos integrados, nas décadas de 1970/80, possibilitou um avanço na produção de computadores.

O crescimento da comunicação baseada na informática foi iniciado por um movimento de jovens metropolitanos cultos que veio à tona no final dos anos 80 . Os atores desse movimento exploraram e construíram um espaço de encontro, de compartilhamento e de invenção coletiva. As tecnologias digitais surgiram, então, como a infra-estrutura do ciberespaço de comunicação, de sociabilidade, de organização e de transação, mas também novo mercado da informação e do conhecimento. [...] Contudo, é necessário expor as grandes tendências da evolução técnica contemporânea para abordar as mutações sociais e culturais que as acompanham. [...] O mundo virtual dispõe as informações em um espaço contínuo - e não em uma rede - e o faz em função da posição do explorador ou de seu representante dentro deste mundo [...]. Neste sentido, um videogame já é um mundo virtual. (LEVY, 1999, p.32;62;125-6). 
A disseminação do uso de computadores como máquinas de uso pessoal ampliou o acesso a um maior número de pessoas e de empresas, intensificando a necessidade de sistematização e disseminação e um número cada vez maior de informações entre usuários.

\section{O novo paradigma das tecnologias digitais na educação}

Na educação, o computador tem sido utilizado para vários fins: em pesquisas, em estudo, programação computacional, entre outros. A introdução da computação nas escolas tem provocado uma verdadeira revolução em nossa concepção de ensino e de aprendizagem. (VALENTE,1991).

Por outro lado, quanto à socialização da informática, a resistência na escola é ainda contundente, inclusive pelo que se tem observado nos resultados de pesquisas sobre a educação ambiental publicados. Muitos professores ainda temem que a utilização de linguagens inovadoras como as possibilidades da hipermídia fragilizam o papel docente no processo de ensino-aprendizagem.

Resultados preliminares de uma pesquisa de doutorado em Mídia e Gestão do Conhecimento realizada pela autora do presente artigo indicam que a escola não só resiste à informática como desconhece quase que totalmente as potencialidades da mesma. Se os professores soubessem utilizar todos os recursos de comunicação que atualmente estão disponíveis, certamente minimizariam as limitações de tempo e de espaço que são os grandes gargalos nos processos de elaboração e gestão do conhecimento. Basta considerar com um pouco de atenção a potencialidade de um sistema hipermediático que possibilita o uso de diversas linguagens ao mesmo tempo e num mesmo espaço. (CATAPAN, 2001).

Um sistema de simulação pode constituir-se num mecanismo de suporte tecnológico no planejamento e implementação de atividades de educação ambiental, por exemplo. Assim, é fundamental que o professor tenha capacidade de perceber fatos e situações de maneira crítica, assumindo posturas respeitosas quanto aos diferentes aspectos e formas do patrimônio humano, seja ele natural, étnico ou cultural.(MELLO, 1999). 
A capacidade e a habilidade de criar, armazenar e acessar informações e documentos digitais é fundamental à permanência e soberania das escolas e das pessoas. A gestão do conhecimento enquanto um processo de monitoração ampliado contribui para uma melhor organização escolar.

As redes de informações contribuem para o enriquecimento da vida acadêmica e para a diminuição das distâncias intelectuais e físicas da comunidade científica, que pode ser tratada como "gestora do conhecimento", em nível mundial.

Assim, as novas tecnologias da informação e da comunicação propiciam uma política de renovação pedagógica e tecnológica, como Escudero (1992, apud Sancho 2001,p.179) assinala:

[...] As novas tecnologias da comunicação exigem, ao serem consideradas sob uma ótica educativa, ser inseridas na categoria mais ampla de programa educacional... Essas tecnologias em conjunto ou qualquer uma delas em particular seriam relacionáveis com o uso pedagógico das mesmas somente se fossem integradas ao contexto do que normalmente se denomina programa educacional... Não entendo, portanto, que possamos falar racionalmente, a partir de uma perspectiva educacional, das novas tecnologias como programas autônomos. (ESCUDERO, 1992, apud SANCHO, 2001, p. 179)

A informática tem sido introduzida como um recurso técnico para ilustrar aulas tradicionais, substituindo o retroprojetor ou quadro negro, ou para simplesmente auxiliar na transmissão de informações. Assim, a informática pode ser uma grande aliada, na medida em que disponibiliza instrumentos de busca, coleta e seleção de informações e conhecimentos. Essas tecnologias de informações e comunicação devem ser utilizadas para integrar a escola e a comunidade.

O conjunto de disciplinas científicas é questionado pelas evoluções pedagógicas do ciberespaço. A abordagem das problemáticas pedagógicas, didáticas, semicognitivas ou sociais que vêm à tona quando se fala do ciberespaço nos faz recordar, antes de tudo, que as tecnologias, outrora chamadas de novas, são, sobretudo, novos dispositivos de comunicação e de informação. Não há formação sem 
comunicação nem comunicação sem midiação das informações e dos dispositivos. Alava (2002) propõe que se conceba todo dispositivo didático em sua dimensão comunicacional.

Para Catapan (2001, p. 143) "[...] o processo de trabalho pedagógico se constitui na indeterminação entre cultura e educação, mediadas pela comunicação que precisa aproximar-se cada vez mais do novo modo de ser, do saber e do apreender dos sujeitos".

O sistema educacional rejeitará a Internet? Essa questão, um pouco provocante, é formulada por Pierre Landry, que analisa igualmente a adesão ou a resistência dos atores e dos professores a tal mudança tecnológica, mas também pedagógica. "As inovações tecnológicas que marcaram a história escolar mostram que a abertura escolar para a vida é técnica é a essência da escola moderna". (ALAVA, 2002, p. 20).

O ciberespaço é um espaço em constante mutação, em conflito e em regulação. Sua utilização como alavanca da aprendizagem repousa sobre a vontade dos formadores e dos responsáveis pela formação em acompanhar essas inovações. "O ciberespaço é hoje um espaço de mobilidade das práticas de formação. Devemos abordá-lo de forma pluridisciplinar, a fim de captar alguns eixos norteadores das inovações futuras". (ALAVA, 2002, p. 21).

A palavra ciberespaço foi inventada em 1984 por William Gibson em seu romance de ficção cientifica Neuromante. Esse termo designa o universo das redes digitais. "Eu defino o ciberespaço como o espaço de comunicação aberto pela interconexão mundial dos computadores". (LEVY, 1999, p 92).

As TICs produzem sentidos e significados sob diversas formas, por meio de registros semióticos distintos: língua natural, linguagens visuais, audiovisuais, textos visuais, entre outros. Por sua configuração técnica e através da rede de determinações que será preciso necessariamente elucidar, as TICs contribuem para a elaboração de sentido e para a construção das representações que veiculam. Em outras palavras, se as TICs, veiculam mensagens, elas contribuem, ao mesmo tempo, para sua significação, impondo-lhes forma e estrutura. (ALAVA, 2002).

A web não é simples instrumento de difusão da informação - é uma verdadeira tecnologia intelectual, uma ferramenta cognitiva no sentido pleno. As ferramentas semióticas são igualmente ferramentas 
cognitivas: pensar também a articulação das teorias das representações materiais de representações cognitivas em outros termos, contribui para o desenvolvimento de uma semiótica cognitiva, constitui uma das tarefas mais urgentes para o desenvolvimento do uso pedagógico de dispositivos midiáticos e do ciberespaço em particular. (ALAVA, 2002).

Todo processo de comunicação implica duas instâncias, emissor e destinatário. Quer se trate de televisão, da web, do correio eletrônico ou da videoconferência, a análise mais corrente da mídia consiste em considerá-la em sua globalidade. (ALAVA, 2002).

No âmbito da ecologia da comunicação que o ciberespaço representa, tornou-se hábito designarmos essas configurações consagradas pelo uso como nichos pedagógicos, tecnológicos e comunicacionais. J. Perriaut (1989, apud ALAVA, 2002, p. 39), afirma que "[...] somos levados a classificar os diferentes usos e as práticas sobre funcionalidades e seus objetivos gerais em termos de comunicação educativa e não suas características técnicas".

E, ainda, "A interatividade geralmente assinala a participação ativa do benificiário de uma transação de informações". (LEVY, 1999, p.93). Assim, a possibilidade de intervir no dispositivo tecnológico ou no ambiente informático (consultar dados, simular, o videogame), na realidade virtual, constitui-se como uma forma de interatividade. Alava (2002) propõe uma classificação dos graus de interatividade dos dispositivos midiáticos em função de diferentes eixos: o grau de personalização das mensagens recebidas, a reciprocidade da comunicação, virtualidade, a incidência da imagem dos participantes no próprio dispositivo e a telepresença.

As tecnologias da informação e da comunicação devem ser utilizadas em um contexto pedagógico renovado, para além da reprodução do modelo de ensino tradicional. A utilização dessas tecnologias deveria levar à mudança na relação pedagógica entre professor e estudante. Sendo a educação um processo interpretativo no qual o sentido é o diálogo e o essencial não é a transmissão de informações, mas a construção de sentido com os aprendizes, a integração de novas tecnologias aos processos ensino-aprendizagem pode assumir várias formas. A elaboração de cursos utilizando-se de 
recursos hipermidiáticos apresenta um interesse particular, pois, a prática abre novos caminhos, tanto em nível de concepção quanto de difusão de conhecimento.

Nesse sentido, Lucena e Fuks (2000) afirmam que:

O acesso ao conteúdo multimídia expande substancialmente a variedade de recursos que o aprendiz pode usar para participar do processo de aprendizado. A natureza assíncrona dá suporte ao aprendizado auto-planejado através de agendas flexíveis; e, tanto o aluno quanto o instrutor decidem quando e onde buscar materiais do curso ou outros recursos. (LUCENA e FUKS, 2000, p. 54).

Aquele que sabe ler domina o conhecimento, o momento em que a abstração e o raciocínio tornam-se ferramentas para o domínio do mundo do saber. É o início da transformação do conhecimento, já expandida pelo hipertexto.

Alava (2002) estabelece três fatores relacionados ao saber:

- O primeiro fator é o da velocidade do aparecimento e do desaparecimento de saberes e habilidades; - o segundo diz respeito à natureza distinta do trabalho, em que a parcela de transação de conhecimentos não pára de crescer; - o terceiro pretende que as TICs amplifiquem, exteriorizem, e modifiquem numerosas funções humanas. (ALAVA, 2002, p. 135).

Quando se fala em produção e evolução do conhecimento, a escola é o principal espaço em que ocorre esse processo. A utilização de TICs leva à evolução do papel do professor no processo de aprendizagem; o novo paradigma sociotecnológico implica que se considere o conceito de inovação em dois níveis: o primeiro nível de utilização das "últimas" tecnologias e o nível de apropriação de uma nova pedagogia que as utilize.

A interatividade é o fator que mais influencia na aprendizagem (HARASIM, 1989, apud, ALAVA, 2002), as infoconferências favorecem o processo de colaboração que muda a natureza da aprendizagem e aumenta sua qualidade. "Poderíamos acreditar que as infoconferências são utilizadas, 
sobretudo na formação a distância". (ALAVA, 2002, p. 145).

A ciberaprendizagem é o terreno por excelência das experiências e das atividades pedagógicas inovadoras. Nela emprega-se a autoformação e criam-se novas abordagens em razão das tecnologias utilizadas.

Essas tecnologias nos oferecem a imagem de um mundo cada vez mais complexo. As ferramentas tecnológicas podem ser excelentes auxiliares de ensino, mas em nenhum caso, concorrerão com o professor. As TICs são suportes para os cursos, mas os professores devem continuar se aperfeiçoando pelo acréscimo de mais interatividade. (ALAVA, 2002, p. 147).

Aprender e acompanhar a evolução do saber tornou-se uma questão sumariamente, importante, nessa nova era do conhecimento, em que as técnicas e as habilidades mudam a um ritmo desenfreado. Para tanto, conforme Levy (1999), estamos em vias de tecer uma enorme rede digital sobre o planeta que, aos poucos, conecta tudo a todos. Imersos nessa rede - o ciberespaço -, nossas culturas nacionais fundem-se lentamente a uma cultura globalizada e cibernética.

Nas palavras de Lévy, estamos vivendo a abertura de um novo espaço de comunicação, e cabe apenas a nós explorar as potencialidades mais positivas desse espaço no plano educacional, econômico, político, cultural e humano.

"Se não se ligar, a escola se desqualificará". Como esse slogan sugere, podemos dizer que as crianças nascem em uma cultura que se clica, e o dever dos professores é inserir-se no universo dos seus alunos (PERRENOUD, 2000, p.125).

As escolas não podem ignorar o que se passa no mundo. As TICs transformam espetacularmente não só nossa maneira de nos comunicar, mas também de trabalhar, de decidir, de pensar... transformam verdadeiramente as próprias condições de trabalho (PERRENOUD, 2000).

No que se refere ao trabalho, Perrenoud (2000, p.134) argumenta, ainda, que os meios de informação são feitos para facilitar as tarefas:

Os softwares de assistência ao trabalho de criação, de pesquisa, de processamento de dados, de comunicação e de decisão são feitos para facilitar tarefas precisas e para melhorar o rendimento 
e a coerência do trabalho humano. Seu domínio obriga a planejar, decidir, encadear operações, orquestrar e reunir recursos. Tudo isso colabora para a formação de competências essenciais, para cuja construção o instrumento é secundário em relação às operações mentais e as qualidades mobilizadas: rigor, memória, antecipação, regulação. (2000, p.143).

A informação é semanticamente significativa, do ponto de vista cibernético. Informação significativa, tanto na máquina quanto no ser humano é a informação que chega a um mecanismo ativador no sistema que a recebe, a despeito dos esforços do homem e ou da natureza para corrompê-la. "Do ponto de vista da Cibernética, a semântica define a extensão do significado e lhe controla a perda num sistema de comunicações". (WIENER, 1993, p. 92-93). O desafio está em perceber as transformações provocadas pelas TICs, assim como nos percebermos e agirmos nesse universo cibernético.

Nesse sentido, o processo de trabalho pedagógico que se constitui na interdeterminação entre cultura e educação mediado por diversas formas de comunicação precisa aproximar-se cada vez mais do novo modo do ser dos sujeitos. "Portanto, o desafio está em descobrir no espaço privilegiado do processo pedagógico as possibilidades de interação que ocorrem na relação professor-aluno, conhecimento mediado pela tecnologia de comunicação digital". (CATAPAN, 2003, p. 117).

Esse é apenas o início de uma discussão que se faz necessária no mundo educativo, que ainda persiste mais situado na resistência às transformações do que inserido nelas.

\section{Notas}

\footnotetext{
${ }^{1}$ Mestre em Geografia e doutoranda no EGC - área de concentração "Mídia e Conhecimento" - UFSC. Professora da UNOCHAPECÓ - SC. Endereço: Avenida Nereu Ramos, 809 E, Ap. 502, Cep: 89801-021, Centro, Chapecó - SC.

E-mail: odete@unochapeco.edu.br
}

\section{Conclusão}


As TICs promovem, tanto na educação básica quanto no ensino superior, a leitura crítica e a produção de informação e comunicação como tema transversal dos conteúdos curriculares das diversas áreas do conhecimento. Isso constitui um novo paradigma para o processo de ensino-aprendizagem requerendo tanto do professor quanto dos alunos mudanças que não diminuirão o esforço disciplinado do estudo, mas podem potencializar o tempo e encurtar os espaços, articulando inúmeros indivíduos numa comunidade de aprendizagem.

A potencialidade da diminuição altera os aspectos cognitivos e relacionais, intensificando a complexidade da interação e a transversalidade dos conhecimentos e criando possibilidades para a construção de outras subjetividades. Se a tecnologia se apresenta nos tempos atuais como uma criação inédita e extraordinária que revoluciona as práticas e o modo de viver e de ser da humanidade, a ela deve corresponder, no domínio da educação, outra criação tecnológica não menos apreciável, que deverá permitir que esses avanços sejam incorporados à prática educativa como novos modos de promoção da autoprodução do ser emancipado.

Porém, ainda são necessários muitos estudos e aprofundamentos para se ter a dimensão de até que ponto as aplicações dessas tecnologias permitem realmente o eficiente acesso à informação e à comunicação dos amplos espectros de conhecimento disponíveis nesse dilúvio de informações?

\section{Referências}

ALAVA, Séraphin. Ciberespaço e formações abertas: Rumo a novas práticas educacionais? Trad. Fátima Murad - Porto Alegre: Artmed, 2002.

CATAPAN, Araci H. Pedagogia e tecnologia: a comunicação digital no processo pedagógico. EDUCAÇÃO. Porto Alegre, ano XXVI, n. ${ }^{\circ}$ 50, junho de 2003, p.109-129 ou Disponível em: www.abed.org.br/ publique/egi/cglua.exe/sys/start

CATAPAN, Araci H.. TERTIUM: o novo modo de ser, do saber e do aprender. Construindo uma taxionomia para mediação pedagógica 
em TCD. Florianópolis: UFSC, 2001 (tese). Encontrado em: http:// www.stela.ufsc.br/ppgep

LÉVY, Piere. Lês Technologies de L'intelligence: Paris: Éditions La Découverte. 1990.

LUCENA, Carlos e FUKS, Hugo. Professores e aprendizes na web: a educação na era da Internet. Rio de Janeiro: Clube do Futuro, 2000.

Paulo: Editora 34, 1999.

Cibercultura. Tradução Carlos Irineu da Costa. São

MELLO, Luiz Emygdio F.(org.) Meio ambiente \& educação. Rio de Janeiro: Gryphus. 1999.

PERRENOUD, Philippe. Dez novas competências para ensinar. Tradução de Patrícia Chittoni Ramos. Porto Alegre: Artes Médicas Sul, 2000.

SANCHO, J. M. Para uma tecnologia educacional. Porto Alegre: Artmed, 2001.

SHILLING, Voltaire. O susto dos mestres. In: Cultura e pensamento, 2006.

VALENTE. J. A. Liberando a mente: computadores na educação. UNICAMP. Campinas: São Paulo, 1991.

WIENER, Norbert. Cibernética e Sociedade: o uso humano de seres humanos. São Paulo: Cultrix LTDA, 1993. 


\title{
Technology and implications for education
}

\begin{abstract}
This article is about Information and Communication Technology (ICTs) and their insertion in several knowledge areas once they have created new possibilities in the interaction among people in different areas, in a world in the interaction among people in different areas, in a world in are increasing process of globalization. The evolution of technologies, since the invention of press, passing through the creation of microcomputers and the Internet allowed a cognitive and relational development. There is necessity of minimum qualification of technical and higher education levels in all areas considering new technologies use.
\end{abstract}

Keywords: Information and Communication Technologies; Education; Paradigm

Recebido em: 18/03/2009

Aceito em: 20/05/2009 
